\title{
Derechos humanos de las personas mayores en la nueva Convención americana y sus implicancias bioéticas
}

\section{Human rights of older people in the new American Convention and its bioethical implications}

\section{Os Direitos humanos das pessoas idosas na nova Convenção americana e suas implicações bioéticas}

Fecha de recepción: 31 de julio de 2015

Fecha de evaluación: 4 de septiembre de 2015

Fecha de aceptación: 26 de octubre de 2015

Disponible en línea: 15 de diciembre de 2015

María Isolina Dabove*

DOI: http://dx.doi.org/10.18359/rlbi.1439

Cómo citar:

Dabove, M. I. (2016). Derechos humanos de las personas mayores en la nueva Convención Americana y sus implicancias bioéticas. Revista Latinoamericana de Bioética, 16(1), 38-59. DOI: http://dx.doi.org/10.18359/rlbi.1439.

Abogada, de la Universidad Nacional de Rosario, Argentina; doctora en Derecho, de la Universidad Carlos III de Madrid, España. Investigadora del Consejo Nacional de Investigaciones Científicas y Técnicas (Conicet-UBA).Directora del Centro de Investigaciones en Derecho de la Vejez, de la Universidad Nacional de Rosario; directora del Observatorio de Derechos Humanos de las Personas Mayores de la Universidad de Morón; directora de la Unidad de Investigación en Derecho de la Vejez de la Facultad de Derecho y Ciencias Sociales, de la Universidad Nacional de Córdoba, Argentina; integrante de la Delegación Oficial Argentina ante la Organización de las Naciones Unidas (ONU) y la Organización de Estados Americanos (OEA) en el proceso de elaboración de la Convención Internacional y de la Convención Americana, de Derechos Humanos de las Personas Mayores. Correo electrónico: isolinadabove@gmail.com. 


\title{
Resumen
}

En este trabajo se estudia al Derecho de la Vejez, en calidad de nueva especialidad jurídica, nacida con el devenir del proceso de especificación internacional de los derechos humanos y la bioética. Por ello, se analiza el impacto jurídico del envejecimiento poblacional, global y multigeneracional, y su desarrollo histórico. Se observa su conexión con la bioética, disciplina filosófica que se despliega en relación con la vida, la salud y la tecnología de la postmodernidad. Se realiza un panorama del contenido y del alcance constitucional del derecho de la vejez, en atención a la condición jurídica de persona de los mayores, a sus derechos de autonomía, participación y prestación, junto a la problemática del acceso a la justicia en la vejez. Además, se analizan el significado y alcance de la reciente Convención Interamericana sobre la Protección de los Derechos Humanos de las Personas Mayores para el Derecho de la Vejez y el Estado constitucional de derecho.

Palabras clave: Derecho de la Vejez, derechos humanos, Convención Americana, estado constitucional de derecho.

\begin{abstract}
This paper studies the Elder Law as a new legal special field, born of the international evolution of human rights through its specification process, developed since 1950. It analyzes the legal impact of the global and multi-generational aging population and the historical development of Elder Law. It treats the connection between Elder Law and Bioethics and makes an overview of the content and scope of Elder Law taking account the legal status of the older person, their rights to autonomy, participation and social rights; together with the issue of access to justice in the old age. Finally, the text discusses the meaning and scope of the recent Inter-American Convention on the protection of human rights of older people to Elder Law and Bioethics.
\end{abstract}

Keywords: Elder Law, human rights, Inter-American Convention, bioetichs.

\section{Resumo}

No pressente trabalho é estudado o Direito da Velhice, referente da nova especialidade jurídica, a qual nasceu com o surgimento do processo de especificação internacional dos direitos humanos e a bioética. Por isso mesmo, é analisado o impacto legal do envelhecimento da população, global e multi-geracional, e seu desenvolvimento histórico. Observa-se sua conexão com a bioética, disciplina filosófica que se desdobra em relação à vida, a saúde e a tecnologia do pós-modernismo. É realizada uma visão geral do conteúdo e do alcance constitucional do direito da velhice, tendo em conta a condição jurídica das pessoas idosas, para seus direitos de autonomia, participação e prestação, em conjunto com a problemática do acesso à justiça na velhice. Além disso, se analisa o significado e o alcance da mais recente Convenção Interamericana sobre a Proteção dos Direitos Humanos das Pessoas Idosas para o Direito da Velhice e o Estado constitucional de direito.

Palavras-chave: Direito da Velhice, direitos humanos, Convenção Interamericana, estado constitucional de direito. 


\section{Introducción}

El Derecho de la Vejez, denominado también Derecho de la Ancianidad, es una nueva especialidad transversal destinada al estudio de la condición jurídica de las personas mayores, de 60 años de edad en adelante, en el derecho interno, regional e internacional. Este derecho se propone también el reconocimiento de las situaciones de aminoración, vulnerabilidad, discriminación, inestabilidad o abusos que puedan padecer estos sujetos, por el hecho de ser "viejos". Pero además aborda el análisis de las herramientas jurídicas que permiten legítimamente la intervención y restitución de la autonomía, libertad, igualdad, participación o dignidad dañadas en el caso. Por ello, en este marco se consideran tanto los principios y reglas, institutos, relaciones jurídicas, derechos y obligaciones, como los sistemas de protección y las garantías, en cuanto se vinculan con el fenómeno demográfico del envejecimiento y de la vejez de cada persona, en particular (Dabove, 2002, 2013a; Dabove y Prunotto Laborde 2006; Frolik y Kaplan, 2003; Dayton y Kimberley 2013, 2014).

Desde el punto de vista ius sociológico, el nacimiento del Derecho de la Vejez está ligado a un fenómeno demográfico y social inédito hasta ahora: el envejecimiento global y multigeneracional. Razón por la cual, esta especialidad no es otra cosa que un intento de respuesta integral, frente a la creciente demanda de fortalecimiento, inclusión y protección de las personas, por el hecho de ser longevas y estar situadas en la última etapa de la vida.
Algunos de los particularismos más significativos que caracterizan a este sector poblacional se derivan de las situaciones de empobrecimiento y exclusión del sistema económico que, con frecuencia, ellos padecen. Otros se asocian a la soledad, a la pérdida de autoestima y a la gerontolescencia, o crisis de identidad, como veremos. Importante es, asimismo, el aumento de los riesgos de sufrir deterioros físicos y cognitivos; los duelos crecientes por la pérdida de seres queridos, o referentes, y la cercanía con la propia muerte; el abandono, el destrato, los abusos y hechos de violencia, tristemente habituales contra ellos. En suma, peculiaridades todas ligadas al declinar biológico, tanto como a las costumbres "edadistas o viejistas": práctica social habitual de generar circunstancias de discriminación en razón de la ancianidad (Dabove, 2002).

Lo cierto es que hoy la vejez nos coloca ante un nuevo desafío jurídico: comprender nuestras propias injusticias respecto de esta etapa de la vida, a fin de resolverlas. Nos sitúa, en efecto, ante la clara percepción de que el mundo no es justo del todo, como señala Amartya Sen. Pero sobre todo, nos impone la convicción de que hay injusticias claramente remediables en nuestro entorno que quisiéramos suprimir.

Por eso, conforme al modelo de Estado neoconstitucional, en el cual se inserta esta nueva rama, el principio de igualdad y no discriminación articula y da sustento normativo y valorativo a la estructura y al desarrollo del Derecho 
de la Vejez. De modo tal que en ella los derechos humanos informan su contenido, abren líneas de interpretación y promueven novedosas figuras jurídicas en pos de un reconocimiento dinámico de las particularidades fácticas de este grupo vulnerable.

Este trabajo habla acerca de estas injusticias, recoge la voz de quienes intentan remediarla y propone directrices para el cambio, que esperamos que sean factibles de sustento en nuestro tiempo. Este aparte hace una lectura jurídica del actual fenómeno global y multigeneracional del envejecimiento; asimismo, observa sus conexiones con el proceso de especificación de los derechos humanos. Pero además, se refiere al impacto del neoconstitucionalismo sobre el desarrollo de esta nueva rama y la protección internacional de este grupo vulnerable.

\section{El envejecimiento global y multigeneracional: su proyección en el derecho de la vejez}

Según los estudios demográficos de la actualidad, la centuria pasada legó a la humanidad la posibilidad cierta de perdurar, a tal punto que hoy, siglo XXI, el envejecimiento es considerado tanto un fenómeno global, como multigeneracional y está caracteriza por varios rasgos (Dabove, 2008): algunos son poblacionales, otros son económicos y también los hay de tipo cultural.

Desde el punto de vista poblacional, se destaca en particular el aumento gene- ralizado y sostenido de la expectativa de vida en todo el mundo. La feminización de la vejez, por la menor mortalidad de las mujeres de edad avanzada, o bien la ampliación cronológica de la vejez como último estadio de la vida, con una duración promedio de 20 años para cada persona.

Otro rasgo para señalar lo constituye la existencia simultánea y en expansión de dos generaciones envejecidas, no siempre vinculadas por lazos de parentesco, junto a la coexistencia de tres o cuatro generaciones de personas partícipes de una misma familia: bisabuelos, abuelos, padres e hijos; a la convivencia de dos generaciones sucesivas de personas envejecidas y vinculadas por lazos de familia: hijos de sesenta y tantos años, con padres que han superado los ochenta, así como a la coincidencia de dos generaciones alternas de familia: abuelos y nietos (Dabove, 2008, pp. 39-54).

Sobre este rico escenario poblacional, la gerontología fue identificando formas variadas de vejez y de envejecimientos, lo cual hizo posible al propio tiempo una más nítida disociación entre la ancianidad normal, respecto del envejecimiento frágil (ligado al padecimiento de algún tipo de discapacidad), tanto como del patológico (o senilidad, vinculada sin más con la enfermedad).

Un ejemplo interesante de este panorama lo representa la República Argentina, donde la esperanza de vida creció notablemente en las últimas cinco décadas. En efecto, durante 1960, el porcentaje 
de personas mayores era de un 5,5\% respecto al total de habitantes. En 1991, el porcentaje ascendió a casi un 8,9 \%; pero en el último censo realizado en 2010 la población adulta mayor alcanzó el 10,2 \%. Para 2020, asimismo, se prevé que los hombres llegarán a alcanzar la edad promedio de 73 años, mientras que las mujeres promediarán los 80 . La proyección para 2050 estima que los hombres rondarán los 77 años y las mujeres podrán llegar a los 84 (Instituto Nacional de Estadísticas y Censos, 2012; Organización de las Naciones Unidas, 2002). Por ello, y haciéndose cargo de este escenario, la Organización de las Naciones Unidas (ONU) ha reconocido sin tapujos que

[...] la notable transición demográfica que se está produciendo hará que para mediados de siglo los porcentajes de la población mundial correspondientes a viejos y jóvenes sean iguales. Según se prevé, el porcentaje de las personas de 60 y más años en todo el mundo se duplicará entre el año 2000 y 2050 y pasará del $10 \%$ al $21 \%$ [...]. (Organización de las Naciones Unidas, 2002).

En el plano económico, el envejecimiento multigeneracional se desenvuelve simultáneamente como un proceso de progresiva dependencia. Al respecto, señala Bellina Yrigoyen que

[...] una de las pérdidas que los ancianos deben afrontar se vincula con el cese de sus actividades laborales lucrativas. No solamente las personas hoy están obligadas a jubilarse, sino que un gran porcentaje percibe un beneficio previsional que no llega a cubrir sus requerimientos. (Bellina Yrigoyen, 2004, p. 15)

En este contexto, poco a poco las generaciones concurrentes tejen entre ellas una compleja red distributiva de recursos, que suele trasladar en la más joven el papel proveedor. Bisabuelos y abuelos con magras jubilaciones y pensiones; hijos integrados al mercado de trabajo que subsidian a sus mayores; nietos jóvenes que se preparan para ello, cual carrera en posta (Di Tullio Budassi, 2008, pp. 64-82; Herrera, 2011, pp. 4-20; Fama y Herrera, 2008; Calvo Ortega y García Calvente, 2007; Ciuro Caldani, 1992, pp. 35-40, 1995, pp. 7-11; Bazo, 1993, pp. 181-192).

La perspectiva cultural muestra, además, que el envejecimiento multigeneracional bien puede ser entendido como una variante del multiculturalismo, del pluralismo político y del plurijuridismo (Kymlica, 1995; Taylor, 1993; Briones, 1998; Prieto Sanchís, 1994, pp. 367-387; Geertz, 2006; Sartori, 2001; Yturbe, 2013). Cada generación esgrime en su haber una forma de entender la vida, códigos de convivencia y prácticas discursivas que le son propios, experiencias políticas diversas, memorias colectivas diferenciables entre sí y valores específicos. Estas culturas interactúan entre sí, se "arrastran" de un grupo a otro, dialogan y compiten, sedimentan y estratifican en un universo heterogéneo de significaciones (De Souza Minayo, 2006, p. 47-59). 
Desde el plano jurídico, esta longevidad global y multigeneracional ha habilitado el sostenimiento cultural del paradigma de la autonomía personal para esta etapa de la vida. Pero además permitió dos reconocimientos internacionales importantes: la capacidad como atributo ineludible de la persona y la adopción concomitante de los sistemas de apoyo y salvaguardas, remedios de las situaciones puntuales y precisas en las cuales sean necesarias restricciones judiciales para el caso.

En suma, el envejecimiento multigeneracional es un fenómeno complejo. Nace con los cambios demográficos de la segunda mitad del siglo XX. Se alimenta del aumento de la esperanza de vida, que permite la convivencia simultánea de varias generaciones; pero también se consolida, como dice Bobbio (1991), con el devenir del tiempo de los derechos y la creciente conciencia del pluralismo jurídico. Es, en suma, un fenómeno social: multitemporal, plurieconómico y multicultural.

Ahora bien, a pesar del auspicioso escenario sociodemográfico actual, "ser viejo" todavía significa vivir sujeto a una triple situación de debilidad, en el mundo jurídico². Así, la dinámica jurídica social torna vulnerable al viejo, por cuanto lo estereotipa y lo constriñe en su ámbito de actuación. El sistema normativo lo debilita por no ofrecerle

2 Respecto de la teoría tridimensional del derecho puede verse a Goldschmidt (1987), Ciuro Caldani (2000), Fundación para las Investigaciones Jurídicas (2000), Rosario (2007). completamente un marco de empoderamiento y protección jurídica, adecuado a las características particulares de su vulnerabilidad. Pero también lo debilitan los valores jurídicos imperantes, cada vez que no reconocen suficientemente a la vejez como un dato diferenciador relevante para el sistema jurídico, fuera del ámbito asistencialista de la seguridad social. En este marco, no resultará extraño entonces que la persona mayor vea debilitada su voluntad y padezca situaciones reales de desprotección jurídica o discriminación. Pero tampoco será infrecuente que su vida y su patrimonio se vean afectados negativamente por causa de las disfuncionalidades de un régimen de capacidad diseñado para una persona abstractamente considerada ${ }^{3}$.

El envejecimiento global plantea una serie de preguntas que no fueron identificadas con claridad sino hasta ahora (Leeson, 2009, pp.47-60, 2009b, pp. 102-124, 2011, pp. 75-80). El Derecho se incorporó a la gerontología apenas hace 30 años y lo hizo a través de un documento "simbólico": la Resolución de la Asamblea Mundial de Naciones Unidas sobre el Envejecimiento, celebrada en Viena en 1982. A partir de entonces -y muy lentamente-, comenzaron a desarrollarse estudios referidos a la responsabilidad estatal hacia las personas mayores, que fueron visibilizando esta cuestión y despertaron la voluntad política de trabajar a favor de su pleno

\footnotetext{
3 Acerca de la discusión en torno a las distintas acepciones de la vejez puede consultarse: Dabove (2002, pp. 103-110).
} 
reconocimiento jurídico. Como veremos en el apartado siguiente, todo ello se fue desarrollando en el marco del proceso de especificación de los derechos humanos, en cuyo seno se plasmó la Convención Interamericana objeto de este estudio.

Asimismo, el Derecho de la Vejez se fue configurando gracias al aporte de la propia bioética, surgida en la década de los setenta, como disciplina filosófica que se despliega en relación con la vida, la salud y la tecnología de la postmodernidad. Este marco disciplinar ofrece una interesante puntualización de principios axiológicos y éticos que permiten fundamentar y legitimar la construcción de esta nueva rama como problemática autónoma formal dentro del derecho. En efecto, desde esta perspectiva encontramos que los derechos de los mayores se pueden interpretar y aplicar siguiendo el criterio valorativo del principio de beneficencia (beneficiar, o al menos no perjudicar), el de autonomía (respecto por las decisiones del sujeto anciano) y el principio de justicia (que exige tratar igual a los iguales, pero desigual a los desiguales). Con los parámetros bioéticos se puede intentar fortalecer la posición de los ancianos dentro del sistema jurídico, en cuanto sujetos situados en condiciones de vulnerabilidad social, frente a los demás individuos y al propio régimen, frente a las circunstancias -sobre todo en relación con la pobreza y a la enfermedad-. Al mismo tiempo también se los podrá fortalecer en relación con el riesgo de generar su propio aislamiento y desintegración.
En Argentina este panorama es el que hizo posible el desarrollo de esta nueva especialidad, llamada Derecho de la Vejez, o Derecho de la Ancianidad; expresiones que aquí usaremos indistintamente por considerarlas adecuadas y valiosas para este tiempo, más allá de la discusión terminológica tratada con amplitud en otros estudios (Dabove, 2002, pp. 120-145).

En la actualidad, esta rama comprende el estudio de cinco cuestiones principales (Dabove, 2006, pp. 25-30):

1. La discriminación por edad, la vulnerabilidad y la capacidad jurídica de las personas mayores.

2. Los derechos humanos de autonomía referidos a la autodeterminación, la libertad y la propiedad en la vejez.

3. Los derechos humanos de participación vinculados a la familia, la inclusión social y la participación política.

4. Los derechos sociales fundados en las exigencias de la igualdad material de las personas mayores.

5. Los sistemas de protección y garantías en orden de asegurar el acceso a la justicia de este grupo.

Cada uno de estos ejes, a su vez, se vincula con uno de los "Cinco principios a favor de las personas de edad", documento que, como sabemos, fue adoptado por la Asamblea General de las Naciones Unidas el 16 de diciembre de 1991 mediante la Resolución 46/91 (Alto Comisionado de las Naciones Unidas para los Refugiados, 2015). Así, 
la problemática de la discriminación por edad, la vulnerabilidad y la capacidad jurídica de las personas mayores está ligada al principio de la autorrealización. El segundo eje, destinado a los derechos humanos de autonomía, se asocia con el principio de independencia. Los derechos humanos de participación, con el principio homónimo (participación). Los derechos sociales se vinculan con el principio de los cuidados, en tanto que el principio de dignidad, por último, informa todo lo relativo a las garantías y los sistemas de protección.

\section{El proceso de especificación de los derechos humanos desde el derecho de la vejez}

El Derecho de la Vejez es fruto de la historia reciente, dentro de la cual se destaca la compleja evolución atravesada por los derechos humanos desde la Edad Moderna. Específicamente, nuestra rama nace y se desarrolla en el marco del proceso de especificación de estos derechos, iniciado por Naciones Unidas a partir de la década de los cincuenta (Bobbio, 1991). Por eso, el Derecho de la Vejez es heredero también de los modelos iniciales de derechos -el inglés, el americano y el francés-, a partir de los cuales fue posible su positivación, generalización e internacionalización (Peces Barba Martínez, 1995, p. 154; Peces Barba Martínez y Fernández García, 1998, t. I y II; Pérez Luño, 1995, p. 52).

En efecto, como nos recuerda Peces Barba Martínez, la positivación fue el resultado de los postulados del iusnaturalismo racionalista, "al centrar el paso del Estado de naturaleza al de sociedad en el contrato social, así como por la justificación, a través suyo, del Poder, cuya primera función soberana era crear el Derecho" (Peces Barba Martínez, 1993, p. 23-112). Fenómenos, todos ellos, que a su vez influyeron decisivamente en el derecho continental y americano. La generalización, por su parte, fue consecuencia de la dimensión de la igualdad formal de los derechos, que se formula en la primera parte del siglo XIX (Dabove, 2002). Un símbolo de ello fue la propia Declaración de los Derechos del Hombre y del Ciudadano (Francia), tanto como los procesos de codificación y el constitucionalismo liberal moderno. Así, cabe recordar que en su artículo primero la propia Declaración afirma que "todos los hombres nacen y permanecen libres e iguales en derechos"4.

El proceso de internacionalización en cambio se fue deduciendo posteriormente a partir del reconocimiento de la igualdad material y del rasgo de universalidad de los derechos (Nino, 2013, pp. 36-42; Bidart Campos, 1991, pp. 29-45); rasgos que, como sabemos, impusieron desde entonces la necesidad de configurarlos más allá del "Ordenamiento Estatal y sin límite de validez espacial [...]" (Peces Barba Martínez, (1993, pp. 154-160). Así pues, en este contexto jurídico, se va a desarrollar el constitucionalismo social

Puede verse en http://www.conseil-constitutionnel.fr/conseil-constitutionnel/root/ bank_mm/espagnol/es_ddhc.pdf 
del siglo XX y nacerá Naciones Unidas en 1945 como garante de los derechos humanos, considerados desde entonces ya no solo generales y abstractos, sino también mundiales (Bidart Campos, 1991, p. 313; Sagûes, 2014, pp. 4-13).

El proceso de especificación llega hasta nosotros como un fenómeno dialéctico y complejo, dentro del cual se pudo amalgamar la afirmación de los derechos civiles y políticos del liberalismo moderno; con la posterior expansión de los derechos económicos, sociales y culturales, del constitucionalismo social contemporáneo. Norberto Bobbio (1991) ha definido este proceso como el paso gradual, pero siempre muy acentuado, hacia una ulterior determinación de los sujetos titulares de derechos. Por ello, supuso una ruptura con el modelo racional y abstracto de la modernidad, y una cierta aproximación al modelo de la igualdad material, al completar la idea de los destinatarios genéricos, los hombres y los ciudadanos, con la de las personas situadas - como mujeres, niños, administrados, consumidores, usuarios de servicios públicos, personas con discapacidad, etc. - y al matizar también los contenidos con la aparición de nuevos derechos, vinculados al medio ambiente, a la paz, al desarrollo, etc. (Dabove, 2002, p. 438).

Así pues, el Derecho de la Ancianidad se presenta hoy en calidad de síntesis dialéctica entre aquella concepción abstracta del ser humano de la modernidad y su versión más radical —material y positiva-, de los contemporáneos (Dabove, 2002, p. 436 ). En esta síntesis, intentan proyectarse los contornos de una idea diferente de lo humano; se expresa, ahora, una concepción referida a un ser humano situado; corpóreo, específico, distinto, necesitado y contingente, pero a la vez genérico e igualmente circunstanciado. Se vislumbra, en suma, una visión de la vida dibujada desde su yo biológico, y también desde su yo histórico y cultural (Dabove, 2002, pp. 440-442).

Por ello, cuando hoy hablamos del niño, del joven y del viejo, o bien del educando y del educador, del varón y la mujer, del científico, del artista, del productor, del empresario, del obrero o del consumidor, lo hacemos pensando en categorías existenciales relevantes, legítimamente diferenciadoras para el mundo jurídico, y en todas ellas no se hace sino aludir a esta manera nueva de percibir la humanidad 5 .

Esta perspectiva quizá pueda explicarnos, asimismo, por qué están apareciendo tantas ramas nuevas en el Derecho como por ejemplo, el Derecho de la Educación, el Derecho de la Ciencia, el Derecho de Informática, el Derecho del Arte, el Derecho de la Salud, el Ecoderecho, el Bioderecho, el Derecho de la Integración, el Derecho de la Cultura y el propio Derecho de la Vejez, el de la Mujer o del Niño, etc. Al respecto ver las comunicaciones presentadas a las "Jornadas de Teoría General del Derecho, Nuevas Fronteras de la Juridicidad". Jornadas organizadas por el Centro de Investigaciones de Filosofía Jurídica y Filosofía Social de la Facultad de Derecho de la Universidad Nacional de Rosario, el Instituto de Estudios Interdisciplinarios y Documentación Jurídica del Colegio de Abogados de Rosario y el Instituto "Werner Goldschmidt" de Investigaciones Jurídicas Especializadas e Interdisciplinarias de la Fundación para las Investigaciones Jurídicas; llevadas a cabo los días 30 de noviembre y 
De esta manera, en esta concepción del ser humano situado se hace referencia al lugar real que ocupan las personas en su circunstancia. Se hace alusión, en suma, al punto de contacto entre el hombre y su realidad, a su condición de sujeto capaz de dar cuentas de sus necesidades, de su libertad y de los modos comunicacionales de su existencia 6 .

En este nuevo despliegue de lo jurídico, observa el profesor Prieto Sanchís, se concede ahora la palabra a unos individuos que ya no pueden hacer abstracción de su historia, ni de su específica condición social. Ni es necesario mutilar parte de su existencia, a la hora de definir los principios de un modelo justo de sociedad (Prieto Sanchís, 1990, p. 57; Nino, 1990, p. 21; Dabove, 2002:, p. 40). Así, desde este paradigma, comenzaron a tener vigencia un gran número de documentos internacionales absolutamente novedosos en esta materia (Bobbio, 1991, p. 110;

1 de diciembre de 1995. Un resumen de las disertaciones puede hallarse en el Boletín del Centro de Investigaciones de Filosofía Jurídica y Filosofía Social, № 21, Rosario, Fundación para las Investigaciones jurídicas, 1996, p. 91 y ss.

$6 \quad$ Aun cuando este "sí mismo" sea poco o esté demasiado recortado, no está aislado. Está atrapado en un cañamazo de relaciones más complejas y más móviles que nunca. Joven o viejo, hombre o mujer, rico o pobre, el sí mismo, siempre está situado sobre nudos de circuitos de comunicación. A partir de este lugar de comunicación, el ser humano situado adquiere significación y poder: presencia. Al respecto ver: Lyotard, JeanFrançois; La condición postmoderna, trad. Mariano Antolín Rato, Buenos Aires, Rei, 1995, p. 37 y ss.
Nikken, 1986, pp. 15, 32). La primera referencia ilustrativa de este proceso es la Declaración de Derechos del Niño que data de 1959; luego se han sucedido, entre muchas otras, la Declaración sobre la eliminación de todas las formas de discriminación de la Mujer, de 1967, la Declaración de Derechos del Disminuido Mental, de 1971, el Plan de Acción Internacional de Viena sobre el envejecimiento, de 1982, los Cinco principios en favor de las personas de edad, de 1991; el Plan de Acción sobre el envejecimiento, de Madrid de 2002; y la última Convención, referida a los Derechos de las Personas con Discapacidad, de 2006.

Ahora bien, en el actual estadio del proceso de especificación, la comunidad internacional sigue compelida a resolver dos problemas relevantes todavía que afectan, asimismo, al Derecho de la Vejez. En palabras de Bobbio, es necesario por un lado aprestar garantías válidas para esos derechos universalmente declarados: por otro lado, urge lograr el perfeccionamiento de su contenido, "articulándolos, especificándolos, actualizándolos, de modo tal que no cristalicen y se vuelvan rígidos en fórmulas, tanto más solemnes cuanto más vacíos [...]" (1991, p. 111).

En el campo particular del Derecho de la Vejez, la comunidad internacional ha ido generando una serie de documentos que contienen principios orientadores, o criterios generales de interpretación jurídica, como los planes mencionados. Pero desde 2003, la Primera Conferencia Regional Intergubernamental sobre Envejecimiento en América Latina y el 
Caribe inició la tarea de construcción de un espacio institucional, para debatir la necesidad de elaboración y el contenido de una Convención Internacional de Derechos Humanos para las Personas de Edad.

A partir de ese momento, los países de la región -particularmente, Argentina, Brasil y Chile-, se han puesto a trabajar intentando generar vías democráticas e incluyentes de participación. Durante los años transcurridos desde entonces, han intervenido en este proceso Gobiernos de la región, organismos de derechos humanos (Organización de las Naciones Unidas [ONU], Centro Latinoamericano de desarrollo Empresarial [Celade], Comisión Económica para América Latina y el Caribe [Cepal], Organización de Estados Americanos [OEA]), universidades, en cuyo marco el Centro de Investigaciones en Derecho de la Vejez de la Facultad de Derecho de la Universidad Nacional de Rosario y el Observatorio de Derechos Humanos de las Personas Mayores de la Universidad de Morón, fueron parte. Pero además colaboraron Organizaciones No Gubernamentales (ONG) vinculadas a la gerontología, tal como es el caso del International Network for the Prevention of Elder Abuse (INPEA) o Help Age, Global Aliance, entre otras.

Gracias a este escenario, varios documentos interesantes se fueron plasmando, entre los cuales cabe destacar la Declaración de Brasilia, del 6 de diciembre de 2007, plataforma político-jurídica desde la cual se impulsó el actual proceso de elaboración de la convención en el seno de Naciones Unidas y en la OEA. Los Estados participantes asumieron así "el compromiso de no escatimar esfuerzos para promover y proteger los derechos humanos y las libertades fundamentales de todas las personas de edad, trabajar en la erradicación de todas las formas de discriminación y violencia y crear redes de protección de las personas de edad para hacer efectivos sus derechos. e ...impulsar la elaboración de una Convención sobre los derechos humanos de las personas de edad en el seno de Naciones Unidas". Las reuniones de seguimiento de la declaración realizadas desde entonces en Argentina, Chile, Brasil y Costa Rica posibilitaron también la identificación de algunos principios valorativos de la futura convención. De ellos se destacan la dignidad, independencia, libertad y autonomía de la persona mayor; la igualdad y no discriminación; la participación e inclusión social de los mayores, y la solidaridad entre generaciones (Dabove y Di Tullio Budassi, 2009).

Sobre esta plataforma general, el 21 de diciembre de 2010, la Asamblea General de Naciones Unidas, mediante la Resolución 65/182, decidió establecer un Grupo de Trabajo de Composición Abierta sobre Envejecimiento (Open Ended Working Group on Ageing).

[...] en el que puedan participar todos los Estados miembros de Naciones Unidas, con el propósito de aumentar la protección de los derechos humanos de las personas de edad 
examinando el marco internacional vigente en materia de derechos humanos de las personas de edad y determinando sus posibles deficiencias y la mejor forma de subsanarlas, incluso mediante el estudio, cuando corresponda, de la viabilidad de nuevos instrumentos y medidas, y solicita al Secretario General que preste a ese grupo de trabajo todo el apoyo necesario, dentro de los límites de los recursos existentes, mientras dure su mandato [...]. (Artículo 28, Resolución 65/182) ${ }^{7}$.

Los grupos de trabajo han sesionado anualmente, desde abril de 2011, en la sede de Naciones Unidas de Nueva York; como resultado de esta tarea, se fueron elaborando diversos informes en los cuales se da cuenta del panorama evolutivo de los derechos humanos de las personas mayores en cada uno de los países participantes. Al mismo tiempo, en este espacio se han podido establecer puntos de partida, mínimos y comunes, por considerar en una futura Convención Internacional de Derechos Humanos de las Personas Mayores. Las reuniones de los grupos son presididas por la República Argentina y asisten representantes de los Estados Miembros de Naciones Unidas, representantes de organizaciones del sistema de la ONU y observadores de organizaciones intergubernamentales y no gubernamentales (United Nation, 2015).

Puede verse en: http://social.un.org/ageing-working-group/
Por último cabe destacar que en 2014 la ONU creo el cargo de "Experto Independiente sobre el disfrute de todos los derechos humanos por las personas de edad". Mucho fue lo que se bregó por su existencia desde los grupos de trabajo de la ONU hasta que, finalmente, se designó a la Mg. Rosa Kornfeld Matte, de Chile, para esa función. Los expertos independientes forman parte de los procedimientos especiales y son nombrados por el Consejo de Derechos Humanos de la ONU. Su misión consiste en examinar e informar sobre temas o cuestiones específicas de derechos humanos. Los expertos ejercen su cargo a título honorario y no forman parte del personal de la ONU ni perciben un sueldo por el desempeño de su mandato. Expresan sus opiniones a título independiente y no representan a sus respectivos Gobiernos ${ }^{8}$.

El logro americano: la primera convención sobre la protección de los derechos humanos de las personas mayores T1

Simultáneamente a este proceso de la ONU, la OEA trabajaba en el desarrollo de un instrumento para su región, en cuyo marco, el 15 de junio de 2015, se aprobó finalmente la Convención Interamericana sobre la Protección de los Derechos Humanos de las Personas Mayores. Este documento, vinculante para todos los países que lo ratifiquen en su derecho interno, es el primero en

8 Puede verse en http://www.ohchr.org/SP/ Issues/OlderPersons/IE/Pages/IEOlderPersons.aspx 
su género y constituye un hito dentro de este proceso de especificación.

Argentina se adhirió muy rápidamente a este nuevo instrumento regional, de modo que, como parte del Derecho Interno, cuenta con jerarquía superior a la ley, habilita a las personas a fundar sus reclamos jurídicos bajo su marco y obliga a todos los operadores y jueces a aplicarla con primacía, incluso respecto del nuevo código civil y comercial de la nación.

En su artículo 1, la convención establece que

[... s su objeto es promover, proteger y asegurar el reconocimiento y el pleno goce y ejercicio, en condiciones de igualdad, de todos los derechos humanos y libertades fundamentales de la persona mayor, a fin de contribuir a su plena inclusión, integración y participación en la sociedad. Por ello, agrega también que todas sus disposiciones no podrán interpretarse como una limitación a derechos o beneficios más amplios o adicionales que reconozcan el derecho internacional o las legislaciones internas de los Estados Parte, a favor de la persona mayor.

Asimismo, los Estados parte se comprometen a adoptar todas las medidas de acción afirmativa que estimen pertinentes a esta convención, con arreglo a sus procedimientos constitucionales y a las previsiones de este documento.
El artículo 2, por su parte, establece una serie de definiciones de palabras clave para el logro de un buen funcionamiento de este texto. Entre otras, se refiere al abandono, a los cuidados paliativos; la discriminación, la discriminación múltiple, el envejecimiento, el envejecimiento activo y saludable, el maltrato, la negligencia. Define el concepto de persona mayor como persona mayor que recibe cuidados a largo plazo, los servicios socio-sanitarios integrados, la unidad doméstica y hogar, y a la propia vejez, a la cual conceptualiza como construcción social de la última etapa del curso de vida.

La convención cuenta, además, con principios propios reconocidos en su artículo 3, cuyo contenido continúa y amplia los cinco principios la ONU, que utilizamos como referencia para el Derecho de la Vejez y en este mismo seminario de trabajo ${ }^{9}$. En tanto que, en

$9 \quad$ Artículo 3: Son principios generales aplicables a la Convención: a) b) c) d) e) f) La promoción y defensa de los derechos humanos y libertades fundamentales de la persona mayor La valorización de la persona mayor, su papel en la sociedad y contribución al desarrollo La dignidad, independencia, protagonismo y autonomía de la persona mayor La igualdad y no discriminación La participación, integración e inclusión plena y efectiva en la sociedad El bienestar y cuidado La seguridad física, económica y social La autorrealización La equidad e igualdad de género y enfoque de curso de vida La solidaridad y fortalecimiento de la protección familiar y comunitaria El buen trato y la atención preferencial El enfoque diferencial para el goce efectivo de los derechos de la persona mayor El respeto y valorización de la diversidad cultural La protección judicial 
su artículo 4, determina cuáles son los deberes generales de los Estados partes en esta materia ${ }^{10}$.

efectiva La responsabilidad del Estado y participación de la familia y de la comunidad en la integración activa, plenay productiva de la persona mayor dentro de la sociedad, así como en su cuidado y atención, de acuerdo con su legislación interna.

10 Artículo 4: Los Estados Parte se comprometen a salvaguardar los derechos humanos y libertades fundamentales de la persona mayor enunciados en la presente Convención, sin discriminación de ningún tipo, y a tal fin: a) Adoptarán medidas para prevenir, sancionar y erradicar aquellas prácticas contrarias a la presente Convención, tales como aislamiento, abandono, sujeciones físicas prolongadas, hacinamiento, expulsiones de la comunidad, la negación de nutrición, infantilización, tratamientos médicos inadecuados o desproporcionados, entre otras, y todas aquellas que constituyan malos tratos o penas crueles, inhumanos o degradantes que atenten contra la seguridad e integridad de la persona mayor. b) Adoptarán las medidas afirmativas y realizarán los ajustes razonables que sean necesarios para el ejercicio de los derechos establecidos en la presente Convención y se abstendrán de adoptar cualquier medida legislativa que sea incompatible con la misma. No se considerarán discriminatorias, en virtud de la presente Convención, las medidas afirmativas y ajustes razonables que sean necesarios para acelerar o lograr la igualdad de hecho de la persona mayor, así como para asegurar su plena integración social, económica, educacional, política y cultural. Tales medidas afirmativas no deberán conducir al mantenimiento de derechos separados para grupos distintos y no deberán perpetuarse más allá de un período razonable o después de alcanzado dicho objetivo. c) Adoptarán y fortalecerán todas las medidas legislativas, administrativas, judiciales, presupuestarias y de cualquier otra índole, incluido un adecuado acceso a la justicia a fin garantizar a la persona mayor un trato dife-
El capítulo 4 de la convención está destinado a la enumeración de los derechos protegidos, atendiendo significativamente a la problemática de la dignidad e integridad de las personas mayores, a la igualdad y no discriminación por razones de edad, al derecho a la vida y a la dignidad en la vejez, al derecho a la independencia y a la autonomía, al derecho a la participación e integración comunitaria, a la seguridad y a una vida sin ningún tipo de violencia, al derecho a no ser sometido a tortura, ni a penas ni tratos inhumanos o degradantes, al derecho al consentimiento libre e informado en el ámbito de la salud, al derecho a recibir servicios de cuidado a largo plazo, al derecho a la libertad personal; de expresión, acceso a

renciado y preferencial en todos los ámbitos. d) Adoptarán las medidas necesarias y cuando lo consideren en el marco de la cooperación internacional, hasta el máximo de los recursos disponibles y tomando en cuenta su grado de desarrollo, a fin de lograr progresivamente, y de conformidad con la legislación interna, la plena efectividad de los derechos económicos, sociales y culturales; sin perjuicio de las obligaciones que sean aplicables de inmediato en virtud del derecho internacional e) Promoverán instituciones públicas especializadas en la protección y promoción de los derechos de la persona mayor y su desarrollo integral. f) Promoverán la más amplia participación de la sociedad civil y de otros actores sociales, en particular de la persona mayor, en la elaboración, aplicación y control de políticas públicas y legislación dirigida a la implementación de la presente Convención. g) Promoverán la recopilación de información adecuada, incluidos datos estadísticos y de investigación, que le permitan formular y aplicar políticas, a fin de dar efecto a la presente Convención. 
la información y circulación, al derecho a la nacionalidad, al derecho a la privacidad y a la intimidad, a la seguridad social, al trabajo, a la salud, a la educación, a la cultura, a la recreación, esparcimiento y al deporte; al derecho a la propiedad, a la vivienda y a disfrutar de un medio ambiente adecuado, al derecho a la accesibilidad y movilidad personal. Reconoce los derechos políticos, el derecho de reunión y de asociación. Se refiere a las situaciones de riesgo y emergencias humanitarias. Resalta el derecho a igual reconocimiento como persona ante la ley. Por último, consagra el derecho al acceso a la justicia.

El capítulo V, por su parte, establece la obligación del Estado y la sociedad de trabajar para el logro de una toma de conciencia integral acerca de los derechos de las personas en esta etapa de la vida ${ }^{11}$.

11 CAPÍtUlO V. Toma de conciencia. Artículo 32: Los Estados Parte acuerdan: a) Adoptar medidas para lograr la divulgación y capacitación progresiva de toda la sociedad sobre la presente Convención. b) Fomentar una actitud positiva hacia la vejez y un trato digno, respetuoso y considerado hacia la persona mayor y, sobre la base de una cultura de paz, impulsar acciones de divulgación, promoción de los derechos y empoderamiento de la persona mayor, así como evitar el lenguaje e imágenes estereotipadas sobre la vejez.

c) Desarrollar programas para sensibilizar a la población sobre el proceso de envejecimiento y sobre la persona mayor, fomentando la participación de ésta y de sus organizaciones en el diseño y formulación de dichos programas. d) Promover la inclusión de contenidos que propicien la compresión y aceptación de la etapa del envejecimiento en
Pero en el capítulo VI se determinan los sistemas de garantías y protección. Para tal fin, la convención prevé la implementación de dos instituciones: la Conferencia de Estados parte y el Comité de Expertos ${ }^{12}$.

La Conferencia de Estados Parte es el órgano principal del mecanismo de seguimiento y está integrada por los Estados parte en la convención. Básicamente, sus funciones son: dar seguimiento al avance de los Estados parte en el cumplimiento de los compromisos emanados de la presente convención; elaborar su reglamento y aprobarlo por mayoría absoluta; dar seguimiento a las actividades desarrolladas por el Comité de Expertos y formular recomendaciones con el objetivo de mejorar el funcionamiento, las reglas y procedimientos de dicho comité; recibir, analizar y evaluar las recomendaciones

los planes y programas de estudios de los diferentes niveles educativos, así como en las agendas académicas y de investigación. e) Promover el reconocimiento de la experiencia, la sabiduría, la productividad y la contribución al desarrollo que la persona mayor brinda a la sociedad en su conjunto.

12 CAPíTULO VI. Mecanismo de seguimiento de la convención y medios de protección. Artículo 33: Mecanismo de Seguimiento Con el fin de dar seguimiento a los compromisos adquiridos y promover la efectiva implementación de la presente Convención se establece un mecanismo de seguimiento integrado por una Conferencia de Estados Parte y un Comité de Expertos El Mecanismo de Seguimiento quedará constituido cuando se haya recibido el décimo instrumento de ratificación o adhesión. Las funciones de la secretaría del Mecanismo de Seguimiento serán ejercidas por la Secretaría General de la Organización de los Estados Americanos. 
del Comité de Expertos y formular las observaciones pertinentes; promover el intercambio de experiencias, buenas prácticas y la cooperación técnica entre los Estados parte con miras a garantizar la efectiva implementación de la presente convención. Resolver cualquier asunto relacionado con el funcionamiento del mecanismo de seguimiento.

El comité, en cambio, estará integrado por expertos designados por cada uno de los Estados parte en la convención y entre sus tareas estarán las siguientes: colaborar en el seguimiento al avance de los Estados parte en la implementación de la presente convención, siendo responsable del análisis técnico de los informes periódicos presentados por los Estados parte. Presentar recomendaciones para el cumplimiento progresivo de la convención sobre la base de los informes presentados por los Estados parte de conformidad con el tema objeto de análisis; elaborar y aprobar su propio reglamento en el marco de las funciones establecidas en el presente artículo.

En cuanto a los recursos procesales, la convención habilita la posibilidad de interponer peticiones individuales ante la Comisión Interamericana de Derechos Humanos, lo cual constituye un avance importantísimo para asegurar la eficacia de sus disposiciones. Concretamente dice el artículo 36:

Cualquier persona o grupo de personas, o entidad no gubernamental legalmente reconocida en uno o más Estados Miembros de la Organización de los Estados Americanos, puede presentar a la Comisión Interamericana de Derechos Humanos peticiones que contengan denuncias o quejas de violación de alguno de los artículos de la presente Convención por un Estado Parte. Para el desarrollo de lo previsto en el presente artículo se tendrá en cuenta la naturaleza progresiva de la vigencia de los derechos económicos, sociales y culturales objeto de protección por la presente Convención. Asimismo, todo Estado Parte puede, en el momento del depósito de su instrumento de ratificación o de adhesión a la presente Convención, o en cualquier momento posterior, declarar que reconoce la competencia de la Comisión Interamericana de Derechos Humanos para recibir y examinar las comunicaciones en que un Estado Parte alegue que otro Estado Parte ha incurrido en violaciones de los derechos humanos establecidos en la presente Convención. En dicho caso, se aplicarán todas las normas de procedimiento pertinentes contenidas en la Convención Americana sobre Derechos Humanos. Los Estados Parte podrán formular consultas a la Comisión en cuestiones relacionadas con la efectiva aplicación de la presente Convención. Asimismo, podrán solicitar a la Comisión asesoramiento y cooperación técnica para asegurar la aplicación efectiva de cualquiera de las disposiciones de la presente Convención. La Comisión, dentro de sus posibilidades, les brindará asesoramiento y asistencia cuando 
le sean solicitados. Todo Estado Parte puede, en el momento del depósito de su instrumento de ratificación o de adhesión a la presente Convención, o en cualquier momento posterior, declarar que reconoce como obligatoria.

Un precedente importante de este avance regional ha sido, sin dudas, la aprobación de la Carta de derechos humanos de las personas mayores de San José de Costa Rica. Esta carta había sido aprobada por los países miembros de la Cepal en 2012, pero su contenido fue el resultado final de la tercera Conferencia Regional Intergubernamental sobre Envejecimiento en América Latina y el Caribe, que se realizó del el 8 hasta el 11 de mayo de ese mismo año ${ }^{13}$.

13 Carta de San José sobre los derechos de las personas mayores de América Latina y el Caribe. Puede verse en http://www.cepal. org/es/publicaciones/carta-de-san-jose-sobre-los-derechos-de-las-personas-mayoresde-america-latina-y-el. En esta carta de San José, los representantes gubernamentales reafirmaron su compromiso expresado en la Declaración de Brasilia de trabajar en la erradicación de todas las formas de discriminación y violencia, y crear redes de protección de las personas mayores para hacer efectivos sus derechos. Respaldaron también la labor del Grupo de Trabajo de las Naciones Unidas de composición abierta sobre el envejecimiento y la del Grupo de Trabajo de la Organización de los Estados Americanos. Los delegados exhortaron a estudiar la viabilidad de una convención internacional y otra interamericana de los derechos de las personas mayores y la designación de un relator especial, encargado de velar por la promoción y protección de los derechos humanos de este colectivo de edad avanzada. Junto a todo ello, los Estados

\section{La recepción constitucional de los derechos humanos en la vejez}

Ahora bien, estas consideraciones relativas a la protección internacional de los derechos humanos de las personas mayores deben ser comprendidas, asimismo, a la luz del paradigma estatal de la postmodernidad: el Estado constitucional de derecho. En este nuevo modelo de organización de la vida jurídica nacional, la Constitución se ha convertido en el eje

expresaron su compromiso de reforzar la protección de los derechos humanos en el ámbito nacional mediante medidas como el trato diferenciado y preferencial hacia las personas mayores; la adopción de leyes especiales de protección; la atención prioritaria a las personas mayores en la tramitación de procesos administrativos y judiciales, así como en los beneficios y prestaciones que brinda el Estado. También señalaron la necesidad de desarrollar políticas públicas y programas dirigidos a aumentar la conciencia sobre estos derechos y su participación en organizaciones de la sociedad civil y en los consejos. Se acordó, además, mejorar los sistemas de protección social para que respondan efectivamente a las necesidades de las personas mayores, por medio de la universalización del derecho a la seguridad social y a la salud. Se instó a la creación de los servicios sociales necesarios para brindarles cuidado, promoviendo a la vez su independencia, autonomía y dignidad. Por otra parte, la Carta de San José hizo hincapié en las obligaciones que tienen los Estados para erradicar las múltiples formas de discriminación que afectan a las personas mayores, con especial énfasis en la discriminación basada en el género y entregar asistencia prioritaria y preferencial a las personas mayores en situaciones de emergencia o desastres naturales. 
fundante de la práctica del derecho en su conjunto. Pero, junto a ella, un papel central lo ocupan también los instrumentos internacionales y regionales referidos a los derechos humanos de este tiempo (Sagues, 2014, p. 7; Nino, 1990, p. 44).

En efecto, el Estado constitucional de derecho es un paradigma jurídico institucional (Amaya, 2014, 2015, p. 2) que puede caracterizarse por: 1) el predominio de la Constitución sobre la voluntad libre del poder legislativo (es decir, el legislador sometido a la Constitución; 2) la preeminencia y vigencia de los derechos fundamentales en todo el ordenamiento jurídico y en la vida social; 3) la instauración de un sistema de control judicial de constitucionalidad de las leyes; y 4) el mayor protagonismo que asumen los jueces a la hora de establecer el contenido específico de lo jurídico14. Todo esto ha provocado en Argentina la incorporación de los tratados, convenciones y declaraciones de derechos humanos, con la reforma de 1994, a nuestra Carta Magna, y así se ha constituido el llamado "bloque de constitucionalidad" de estos derechos (artículo 75, inciso 23). Pero además ha provocado la constitucionalización del derecho privado, tanto como la del ámbito público en su conjunto (Dabove y Barbero, 2009, pp. 13-46).

$14 \quad$ La Constitución que rige en el Estado constitucional de derecho tiene atribuidos caracteres y asume ciertos roles que no necesariamente están presenten en las leyes supremas de los Estados de derecho del siglo XIX. Puede verse al respecto, Prieto Sanchís (2002).
Así, pues, la adopción del modelo neoconstitucional fue generando la confusión de las fronteras tradicionalmente vigentes entre la Constitución y el derecho privado. (Arce y Flórez-Valdés, 1991; García Torres y Jiménez-Blanco, 1986). Ha motivado, también, el aumento de los requerimientos de los operadores jurídicos para que el juez iusprivatista formule una lectura constitucional de las cuestiones de derecho privado que plantean. Pero además, el propio derecho privado ha incorporado para sí el recurso a los principios y su método de aplicación: el juicio de ponderación, razonabilidad, o proporcionalidad (artículo 28 de la Constitución Nacional Argentina) (Ariza, 2003), como se observa en el flamante código civil y comercial argentino. Así pues, en el derecho privado cada vez con mayor frecuencia nos encontramos ante mandatos de optimización -al decir de Alexy- que exigen su cumplimiento en la mayor medida posible. Receptan derechos humanos fundamentales (Dabove y Barbero, 2009, p. 13-46) y operan como normas elásticas que pueden aplicarse en grados diversos, según las exigencias de los casos concretos sometidos a juzgamiento; a diferencia de lo que ocurre con las reglas (Alexy, 1993, pp. 82-87; Prieto Sanchis, 1993, p. 53; Bernal Pulido, 2003, p. 75).

En suma, el Estado constitucional de derecho requiere que los principios -o derechos humanos-constitucionalmente receptados se apliquen en la mayor medida posible; o bien, que tengan la 
mayor expansión posible. Con una única excepción: el respeto por el orden públi$\mathrm{co}$, la moral y las exigencias igualmente fundamentales de un derecho constitucional contradictorio ${ }^{15}$. Así, desde este nuevo modelo de Estado y de derecho, la aprobación de una Convención Internacional de Derechos Humanos de las Personas Mayores resulta central, por cuanto asisten en su favor razones demográficas, sociales, económicas y políticas suficientes, como hemos visto en este trabajo. Pero además es vital lograr receptarla con las mayorías previstas en la Carta Magna argentina a fin de que integre el bloque de constitucionalidad del artículo 75, inciso 23.

En este sentido, cabe recordar que la última incorporación lograda en este carácter ha sido la de la Convención Internacional de Derechos de las Personas con Discapacidad, cuyo rango constitucional recién lo alcanzó en 2014, es decir, siete años después a su entrada en vigencia en el derecho interno argentino (Argentina, Ley 27.044); lugar desde el cual ha podido incluso impactar en el nuevo código civil y comercial argentino mencionado, ya que sus principios y su

15 Así por ejemplo, en un Estado que sea verdaderamente constitucional, todas las personas deben gozar de la libertad y la igualdad en la mayor medida posible. De modo tal que los límites que el Estado quiera imponer a la libertad o la igualdad de una persona deben estar justificados en una razón válida y razonable. Caso contrario, el límite impuesto por el Estado deviene inconstitucional (Dabove y Barbero, 2009, pp. 15 y ss). espíritu informan su contenido, expresado sobre todo en el título preliminary en título I referido a la persona humana, al nuevo régimen de la capacidad, los sistemas de apoyo, la tutela y la curatela, a través de sus artículos 22 a 24 y 31 al 50 , entre otros.

\section{Conclusiones}

El envejecimiento poblacional, globaly multigeneracional es un fenómeno afortunadamente irreversible. El progreso en la calidad de vida de los mayores ha hecho posible que los niños nacidos en ese siglo cuenten ya con una expectativa de vida centenaria. El Derecho de la Vejez, o de la Ancianidad, intenta dar respuestas jurídicas a la creciente cantidad de necesidades y conflictos nuevos que aquel genera.

En este trabajo hemos "pasado revista" al contenido de esta nueva disciplina, a sus principios y a su historia. Los derechos humanos y el modelo neoconstitucional del Estado actual y de la comunidad internacional sustentan su desarrollo y auguran el nacimiento de nuevas herramientas que hagan realidad la aspiración de construir una sociedad para todas las edades (ONU). "Lo que nos mueve, con razón suficiente -como nos recuerda Amartya Sen-, no es la percepción de que el mundo no es justo del todo, lo cual pocos esperamos, sino que hay injusticias claramente remediables en nuestro entorno que quisiéramos suprimir" (Sen, 201, p. 11). 


\section{Referencias}

Alexy, R. (1993). Teoría de los derechos fundamentales (Garzón Valdés, E. trad.). Madrid: Centro de Estudios Constitucionales.

Alto Comisionado de las Naciones Unidas para los Refugiados (Acnur) (2015). Principios de las Naciones Unidas a favor de las personas de edad. Recuperado el 12 de febrero de 2015, de http:// www.acnur.org/t3/fileadmin/scripts/ doc.php?file=t3/fileadmin/Documentos/ BDL/2003/1640, el 2 de marzo de 2015.

Amaya, J. A. (2014). Control de constitucionalidad (2da. Edición). Buenos Aires-Bogotá: Astrea.

Amaya, J. A. (2015). Democracia y minoría política. Buenos Aires-Bogotá: Astrea.

Ansuategui Roig, F. J. De Asís Roig, R., Fernández García, E., Fernández Liesa, C.R. y Peces-Barba Martínez, G. (Dirs.), Historia de los derechos fundamentales (pp. 29-0). Madrid: Dykinson.

Arce y Flórez-Valdés, J. (1991). El derecho civil constitucional. Madrid: Civitas.

Ariza, A. (23 de abril de 2003). Emergenciay sistema de derecho privado. Suplemento Lexis Nexis.

Bazo, M. T. (1993). La vejez como problema social. En P. Sánchez Vera (Ed.), Sociedad y Población Anciana (pp. 181-193). Murcia: Universidad de Murcia.

Bellina Yrigoyen, J. (2004). La economía política de los fondos de pensiones. Rosario: Universidad del Centro Educativo Latinoamericano [UCEL].

Bernal Pulido, C. (2003). El principio de proporcionalidad y los derechos fundamentales. El principio de proporcionalidad como criterio para determinar el contenido de los derechos fundamentales vinculante para el legislador. Madrid: Centro de Estudios Políticos y Constitucionales.

Bidart Campos, G. (1991). Teoría general de los derechos humanos. Buenos aires: Astrea.

Bobbio, N. (1991). El tiempo de los derechos (De Asís Roig, R. trad.). Madrid: Sistema.

Briones, C. (1998). La alteridad del cuarto mundo. Buenos Aires: Colihue.

Calvo Ortega, R. y García Calvente, Y. (2007). Situaciones de dependencia: regulación actual y nuevas perspectivas. Pamplona: Thomson, Civitas.

Ciuro Caldani, M. A. (1992). Derecho de la Ancianidad. Investigación y Docencia, (20), 35- 40.

Ciuro Caldani, M. A. (1995). Comparación jusfilosófica del Derecho de Menores y el Derecho de la Ancianidad. Investigación y Docencia, (25), 17-32.

Ciuro Caldani, M. Á. (2000), La conjetura del funcionamiento de las normas jurídicas. Metodologíajurídica. Rosario: Fundación para las Investigaciones Jurídica.

Ciuro Caldani, M. Á. (2000). Metodología jurídica y lecciones de historia de la filosofía del derecho. Rosario: Fundación para las Investigaciones Jurídicas.

Dabove, M. I. (2002). Los derechos de los ancianos (2da. edición). Buenos Aires: Ciudad Argentina.

Dabove, M. I. (julio-agosto, 2008). Derecho y multigeneracionismo: o los nuevos desafíos de la responsabilidad jurídica familiar en la vejez. Revista de Derecho de Familia, (40,), 39.54

Dabove, M. I. (septiembre, 2013a). Elder law: a need that emerges in the course of life. Ageing International, 40, 138.148. 
doi 10.1007/s12126-013-9193-4.

Dabove, M. I. (2013b). Ciudadanía y derechos fundamentales de las personas mayores: de las políticas gerontológicas al Derecho de la Vejez. Revista de la Facultad de Derecho y Ciencias Sociales, 4(1), 19-36. Recuperado el 20 de mayo de 2014, de http://www.derecho.unc.edu.ar/revistas/ revista-de-la-facultad-de-derecho/vol.iv-no-1-nva.-serie-ii-2013/view

Dabove, M.I. y Barbero, D. O. (2009). Igualdad y no discriminación en los actos de autoprotección: nuevas zazones para la acción en favor de los derechos de los grupos vulnerables. Revista del Instituto de Derecho e Integración, (1), 13-46.

Dabove, M. I. y Di Tullio Budassi, R. G. (2009). Bases y puntos de partida para la convención internacional de derechos humanos en la ancianidad: la calidad de vida como meta. X Congreso Nacional de Sociología Jurídica. Legalidad y Legitimidad: confrontaciones sociales en torno al Derecho. Córdoba, Consejo Latinoamericano de Ciencias Sociales [Clacso], Universidad Nacional de Rosario [UNC], Sociedad Argentina de Sociología Jurídica.

Dabove, M.I. y Prunotto Laborde, A. (Dirs) (2006). Derecho de la Ancianidad. Perspectiva interdisciplinaria. Rosario: Juris.

De Souza Minayo, M. C. (2006). Visâo antropológica do envelhecimento humano, en Velhices. Reflexôes contemporáneas. San Pablo: Pontificia Universidad católica de Sao Paulo.

Dayton, K.A. (2013). Elder law: readings, cases, and Materials (4ta. edición). Durham: Carolina Academic Press.

Dayton, K. A. (Ed.) (2014). Comparative perspectives on adult guardianship, Durham: Carolina Academic Press.
Di Tullio Budassi, R. (20080). El derecho alimentario de los ancianos. Derecho de Familia. Revista Interdisciplinaria de Doctrina y Jurisprudencia, (38), 64-82.

Fama, M. V. y Herrera, M. (17 de noviembre de 2008). La obligación alimentaria de los abuelos hoy, Revista Jurídica online El Dial, (2659), 34-52.

Frolik, L. A. y Kaplan, R. L. (2003). Elder law (3ra. Edición). St. Paul: Thomson West.

Garcia Torres, J. y Jiménez-Blanco, A. (1986). Derechos fundamentales y relaciones entre particulares. Madrid: Civitas.

Geertz, C. (2006). Los usos de la diversidad. Barcelona: Paidós.

Goldschmidt, W (1987). Introducción filosófica al derecho. La teoría trialista del mundo jurídico y sus horizontes (6ta. edición). Buenos Aires: Depalma.

Herrera, M. (16 de marzo de 2011). Estado, ciudadanía y democracia. Algunos silenciados del derecho de familia: el papel de los abuelos en la familia del siglo XXI. Jurisprudencia Argentina, 4-20.

Instituto Nacional de Estadísticas y Censos (Imdec) (2012). Encuesta Nacional sobre Calidad de Vida de Adultos Mayores 2012-Encaviam, principales resultados. Serie Estudios Indec, (46), 9-21.

Kymlica, W. (1995). Ciudadanía multicultural. Barcelona: Paidós.

Leeson, G. W. (20110). Prepared or not, Latin America faces thecChallenge of aging, current history. Journal of Contemporary World Affairs, 110(733), 75-80.

Lesson, G. W. (2009a). Future ageing in southeast Asia: demographic trends, human capital and health status. En E. Nurvidya y A. Ananta (Eds.), Older Persons in Southeast Asia (pp. 32-41). 
Singapore: Institute of Southeast Asian Studies (Ieas).

Lesson, G. W. (2009b). Demography, politics and policy in Europe. En P. Ludow (Ed.), Setting EU Priorities 2009. Portugal: The European Strategy Forum.

Nikken, P. (1986). Los derechos del niño, de los ancianos y de la mujer: su protección internacional. Revista del Instituto Interam0ericano de Derechos Humanos, (4), 79-84.

Nino, C. S. (1990). Autonomía y necesidades básicas. Doxa, (7), 73-79.

Nino, C. S. (2013). Fundamentos de derecho constitucional (lera. edición). Buenos Aires: Astrea.

Organización de las Naciones Unidas (ONU) (2002). Segunda Asamblea Mundial sobre el Envejecimiento Madrid, España, 8 a 12 de abril. Plan de Acción Internacional de Madrid sobre el Envejecimiento 2002. Recuperado de http:// social.un.org/index/Portals/0/ageing/ documents/Fulltext-SP.pdf> [Consulta: 25 de junio de 2013].

Peces Barba Martínez, G. (1995). Curso de derechos fundamentales. Madrid: BOE-Universidad Carlos III de Madrid.

Pérez Luño, A. E. (1995). Derechos humanos, estado de derecho y constitución (5ta. edición). Madrid: Tecnos.

Prieto Sanchis, L. (1992). Sobre principios y normas. Problemas del razonamiento jurídico. Madri d: Centro de Estudios Constitucionales.

Prieto Sanchis, L. (1994). Minorías, respeto a la disidencia e igualdad sustancial, en Doxa, (15-16), 367-387.
Prieto Sanchís, L. (2002). Derechos fundamentales, neoconstitucionalismo y ponderación judicial. Lima: Palestra.

Peces Barba Martínez, G. y Fernandez García, Eusebio (1998). Historia de los Derechos Fundamentales. Madrid: Dykinson.

Peces Barba Martínez, G. (1993). Derecho y derechos fundamentales. Madrid: Centro de Estudios Constitucionales.

Perez Luño, A. E. (1995). Derechos humanos, estado de derecho y constitución (5ta. edoción). Madrid: Tecnos.

Prieto Sanchis, L. (1990). Estudios sobre derechos fundamentales. Madrid: Debate.

Rosario, Z. (2007). Estrategia jurídica. Rosario: UNR Editora.

Sagûes, N. P. (2014). Manual de derecho constitucional (2da. edición). Buenos Aires: Astrea.

Sartori, G. (2001). La sociedad multiétnica. Pluralismo, multiculturalismo y extranjeros. Madrid: Taurus.

Sen, A. (2011). La idea de justicia (Valencia Villa, H. trad.). Buenos Aires: Aguilar, Altea, Taurus, Alfaguara.

Taylor, C. (1993). Multiculturalismo y la política del reconocimiento. México, D. F: Fondo de Cultura Económica.

United Nation (2015). Open-ended Working Group on Ageing for the purpose of strengthening the protection of the human rights of older persons. Recuperado de http:// social.un.org/ageing-working-group/ (Consulta: 2 de marzo de 2015).

Yturbe; C. de (2008). Multiculturalismo y derechos. México, D.F: Instituto Federal Electoral. Recuperado el5 de junio de 2013, de http://biblio.juridicas.unam. mx/libros/1/490/1.pdf 